\title{
Medicina como Nova Graduação: Motivações, Dificuldades e Expectativas
}

\author{
Medicine as a New Undergraduate Degree: \\ Motivations, Challenges and Expectations
}

\author{
Ricardo Dias Corrêa \\ Rafaela Cristina Brito Gonçalves ${ }^{I}$ \\ Letícia Santos de Oliveira ${ }^{I}$ \\ Vinícius Coelho Machado Silval \\ Maria Mônica Freitas Ribeiro ${ }^{I}$
}

\section{PALAVRAS-CHAVE \\ - Estudantes de Medicina; \\ - Motivação; \\ - Escolha da Profissão; \\ - Educação Médica.}

\section{KEYWORDS}

- Students, Medical;

- Motivation;

- Career Choice;

- Medical Education.

Recebido em: 16/09/2014

Reencaminhado em: 04/09/2015

Aprovado em: 13/05/2016

\section{RESUMO}

Os motivos que levam graduados a iniciarem novo curso superior em Medicina têm sido pouco estudados, principalmente no Brasil. O objetivo deste trabalho foi conhecer os motivos que levam um profissional já graduado a iniciar um novo curso, especificamente Medicina, as dificuldades para cursá-lo e as expectativas profissionais. Metodologia: Estudo transversal com estudantes de Medicina já graduados em outros cursos superiores. Utilizou-se questionário com questões abertas e fechadas. Análise descritiva dos dados quantitativos e análise de conteúdo dos dados qualitativos foram realizadas. Dos 110 estudantes já graduados em outro curso matriculados na faculdade no período estudado, 49\% (54) participaram da pesquisa. A faixa etária predominante foi de 29 a 33 anos. Os graduados ingressam no curso médico em busca de maior valorização pessoal e profissional, não alcançada no primeiro curso, principalmente melhores remuneração e empregabilidade. Embora ter completado um curso superior traga benefícios ao ingressar num segundo, há também dificuldades, uma vez que muitos já constituíram família ou precisam trabalhar. Em relação às expectativas, o desejo de obter independência financeira coexiste com a intenção de realizar a especialização em residência médica.

\section{ABSTRACT}

There is, especially in Brazil, a lack of papers about people's reasons for opting to study medicine after graduating in other areas. The aim of this study was to understand the reasons that lead a professional to embark on a new course, specifically medicine, the difficulties involved and professional expectations. Methodology: A cross-sectional study with medical students already graduated in other areas, using a structured self-administered form with open-ended and closed-ended questions. Descriptive analysis of quantitative data and content analysis of qualitative data were performed. Of the 110 graduates enrolled during the studied period, 49\% took part in the research. The predominant age was 29 to 33 years. Graduates enter the medical course in pursuit of greater personal and professional valuation not achieved with their first qualification, including, especially, better remuneration and employability. Although completing a higher education course brings benefits when starting a second one, there are also difficulties since many of the graduates have already established a family or need to work. In relation to expectations, despite the desire to achieve financial independence, specialization in medicine is usually the goal. 


\section{INTRODUÇÃO}

Os motivos que levam à opção pelo curso de graduação em Medicina, bem como o perfil dos estudantes têm sido amplamente estudados ${ }^{1,2,3}$. Entretanto, poucos trabalhos investigaram os motivos que levam egressos de cursos superiores a iniciarem uma nova graduação ${ }^{4-7}$, especificamente a Medicina. Não foi encontrado nenhum trabalho brasileiro anterior a esta pesquisa realizado com esta perspectiva.

Este trabalho teve como objetivo geral investigar os motivos que levam um profissional a optar por uma nova graduação e verificar que possíveis fatores determinaram a escolha da Medicina. Seus objetivos específicos foram investigar o perfil socioeconômico desses estudantes e verificar o impacto da nova graduação em suas vidas; as dificuldades de fazer o curso; as estratégias usadas para completar o curso; se houve influências, principalmente quanto à capacidade de aprendizado, do primeiro curso sobre o atual; e que expectativas esses estudantes apresentavam quanto ao exercício da nova profissão.

\section{PESSOAS E MÉTODOS}

Trata-se de estudo transversal, observacional, realizado com estudantes do primeiro ao décimo segundo período do curso de Medicina da Faculdade de Medicina da Universidade Federal de Minas Gerais (UFMG) que haviam terminado um curso de graduação em nível superior antes de iniciarem o curso de Medicina. O tempo proposto para a coleta dos dados foi de dois semestres letivos consecutivos. O projeto obteve aprovação do Comitê de Ética em Pesquisa da UFMG (CAAE: 00993112.7.0000.5149).

A Faculdade de Medicina da UFMG é uma escola pública, federal, que admite 320 novos alunos por ano. Situa-se numa capital do Sudeste brasileiro. O curso de Medicina ocorre em horário integral, e os dois primeiros anos, à época do estudo, aconteciam no Instituto de Ciências Biológicas; as disciplinas apresentavam conteúdo predominantemente biológico, com aulas teóricas e em laboratórios. A partir do terceiro ano, o curso se caracterizava predominantemente por atividades assistenciais supervisionadas, em pequenos grupos. Os cenários de prática eram ambulatórios e enfermarias do hospital-escola, centros de saúde e unidades de pronto atendimento da rede pública do Sistema Único de Saúde (SUS), além de atividades em pequenos municípios do estado durante o Internato em Saúde Coletiva ${ }^{8}$.

Os estudantes foram convidados a participar, e aqueles que concordaram assinaram o Termo de Consentimento Livre e Esclarecido. Como não foi possível acessar os dados pessoais dos estudantes da instituição, estes foram identifi- cados por colegas de turma que indicavam quais já haviam concluído outro curso superior. O convite foi feito pessoalmente em áreas do campus, por e-mail, redes sociais ou por telefone, quando se explicitavam os objetivos da pesquisa. Os dados foram coletados por meio de um questionário aberto e autoaplicável, elaborado pelos próprios pesquisadores a fim de investigar as motivações para cursar uma nova graduação; as razões para escolha da Medicina; as dificuldades para estudar Medicina e os meios para contorná-las; e as expectativas e opções em relação ao futuro exercício profissional, além de dados demográficos individuais de interesse para a pesquisa. Foi realizado um estudo piloto para se avaliar a compreensão das perguntas.

Para a análise qualitativa das respostas, utilizou-se a metodologia qualitativa de análise de conteúdo. As respostas foram lidas individualmente por quatro pesquisadores, que fizeram uma categorização das mesmas. Depois, essas categorias foram avaliadas em conjunto, buscando categorias comuns. Quando houve dúvidas, voltou-se ao questionário e buscou-se obter um consenso. Quando não houve concordância, um quinto pesquisador, que não participou da categorização inicial, determinava qual a categoria mais pertinente. Após a categorização, foi calculada a frequência para cada categoria. Alguns exemplos representativos de cada uma são descritos nos resultados.

Os dados quantitativos foram organizados em banco de dados no Excel, e a análise descritiva obtida por meio do software SPSS (versão 17.0). Os insumos para a pesquisa foram doados pelos pesquisadores.

\section{RESULTADOS}

De acordo com o Departamento de Registros e Controle Acadêmico da UFMG, o número de estudantes já graduados ingressantes no curso de Medicina no período avaliado (entradas entre 2007 e 2012) foi de 110 alunos, o que correspondeu a $6 \%$ do total daqueles matriculados em Medicina. Considerando-se as dificuldades para identificá-los, uma vez que não foi permitido acesso aos dados institucionais dos estudantes, a amostra total deste estudo foi de 54 alunos (49\%), sendo que três deles se recusaram a participar da pesquisa.

A Tabela 1 apresenta a distribuição da amostra segundo idade, sexo, estado civil e se possui filhos. Percebe-se que houve predomínio da faixa etária de 29 a 33 anos. A média de idade foi de $31 \pm 4$ anos. Solteiros predominaram com $71 \%$, seguidos por casados ( $24 \%$ ), sendo que, do total, $16 \%$ tinham filhos. Dos participantes, $48 \%$ eram mulheres e $52 \%$ homens. 


\begin{tabular}{|c|c|c|}
\hline $\begin{array}{r}\mathrm{D} \\
\text { medi } \\
\mathrm{m}\end{array}$ & $\begin{array}{c}\text { TABELA } 1 \\
\text { ográficos dos e } \\
\text { raduados em } 0 \\
\text { o estudo. FM- }\end{array}$ & \\
\hline & Item & $\%$ \\
\hline & 24 a 28 anos & 21,6 \\
\hline Fairgetári & 29 a 33 anos & 54,9 \\
\hline Faıxa etarıa & 34 a 38 anos & 17,6 \\
\hline & 39 a 43 anos & 5,9 \\
\hline & Solteiro & 70,6 \\
\hline & Casado & 23,5 \\
\hline Estado civil & União estável & 3,9 \\
\hline & Divorciado & 2,0 \\
\hline Possui filhos & & 15,7 \\
\hline
\end{tabular}

A média de idade dos entrevistados ao ingressarem no primeiro curso de graduação foi 20 anos, com variação entre 17 e 24 anos. Após a conclusão da primeira graduação, 22\% iniciaram outro curso superior antes da Medicina.

Pelo Gráfico 1, percebe-se que a maior parte da amostra é composta por egressos do curso de Farmácia (31\%), seguidos por Enfermagem (16\%) e Ciências Biológicas (6\%). Chama a atenção o fato de cerca de $10 \%$ dos alunos terem formação em cursos não relacionados à área biomédica, como Física, Engenharia Mecânica e Comunicação Social.

Cerca de $40 \%$ desses estudantes possui título de pós-graduação, sendo especialização lato sensu o mais frequente (74\%), seguido por mestrado (26\%). A maior parte (78\%) exerceu a profissão por um período médio de quatro anos e quatro meses antes de iniciar o curso de Medicina.

Ao ingressar no curso de Medicina, a média de idade foi de $30 \pm 4$ anos, com variação de 23 a 42 anos. O principal meio de ingresso foi o vestibular (94\%), que demandou uma média de $2 \pm 1$ concursos. Quanto à situação no curso, 94\% estavam em situação regular, ou seja, cursando apenas disciplinas de um mesmo semestre. Pouco mais de um quarto (27\%) dos entrevistados ainda exercia a profissão anterior durante o curso médico.

Aproximadamente metade dos estudantes (43\%) morava com os pais, $21 \%$ com o cônjuge, $16 \%$ em moradias estudantis (repúblicas), $12 \%$ sozinhos e $6 \%$ com outros familiares. Para a manutenção econômica, 34\% contavam com ajuda dos pais, $26 \%$ trabalhavam na profissão anterior e $18 \%$ trabalhavam em outra profissão. $\mathrm{O}$ valor médio sugerido como necessário para se manter foi de cerca de $\mathrm{R} \$ 1.500,00$, variando de $\mathrm{R} \$ 500,00$ a $\mathrm{R} \$ 4.000,00$.
GrÁFICO 1

Distribuição dos estudantes de medicina, já

graduados em outros cursos, segundo a graduação anterior à medicina. FM- UFMG 2012

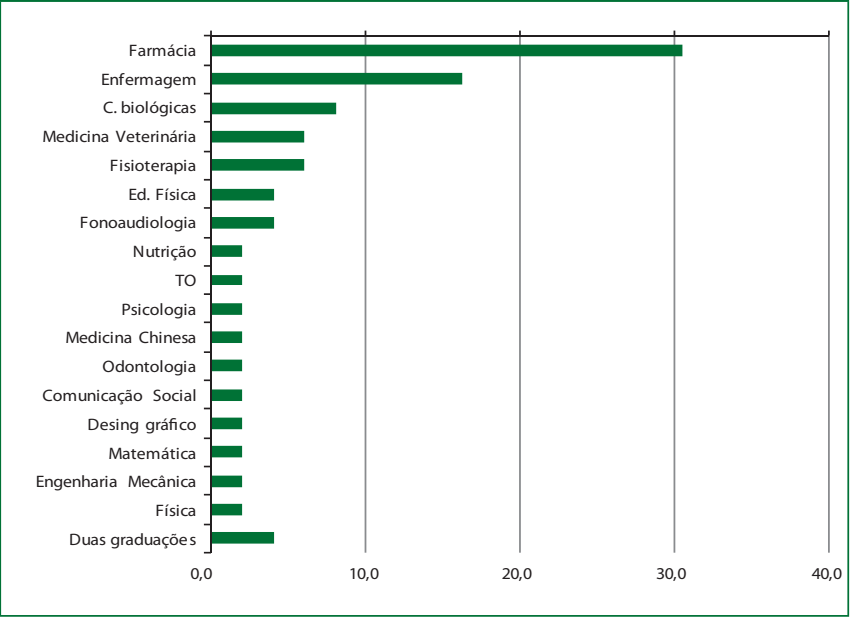

C. biológicas $\rightarrow$ C. Biológicas

Desing $\rightarrow$ Design

Os resultados obtidos após categorização das respostas às questões são descritos a seguir.

Em relação aos fatores que levaram à opção por realizar outra graduação, o mais citado foi a insatisfação com a profissão anterior (22\%), seguido do desejo antigo de ser médico (16\%) e da busca por remuneração e mercado de trabalho melhores (16\%).

\footnotetext{
"Porque estava infeliz com minhas outras profissões (educação física e nutrição) ".

"[...] busca de perspectiva salarial melhor e mais coerente com responsabilidade de atuação".

"[...] o curso anterior não tinha bom mercado de trabalho".

"[...] sempre quis fazer medicina e, por estar insatisfeito com o curso de farmácia, resolvi fazer uma nova graduação".
}

Já a busca por melhores condições salariais (20\%) e inserção no mercado de trabalho (15\%) foram os principais motivos para a escolha, especificamente, do curso de Medicina. Em seguida, relataram a busca por realização de um sonho (14\%), valorização pessoal e status social da profissão (12\%).

\footnotetext{
"[...] considero a medicina [...] com melhores salários".

"[...] mercado de trabalho favorável e principalmente pela ausência contínua desse profissional em meu município".

"[...] queria status social".

"Sempre foi a graduação que eu quis antes do meu primeiro vestibular".
} 
Apenas 20\% dos entrevistados afirmaram manter atividade atual relacionada ao primeiro curso. Desses, a maioria o faz por ainda trabalhar com a profissão anterior (70\%), seguido por manter relações interpessoais com antigos colegas (20\%) e realizar leituras vinculadas ao antigo curso (10\%).

"Trabalho como psicóloga na rede pública de saúde".

"Apenas o contato feito com pessoas que fizeram o mesmo curso".

"Tenho pouco contato com farmácia, ainda que continue lendo muito sobre medicamentos".

Os entrevistados ainda apontaram os principais fatores de satisfação e frustração relacionados ao primeiro curso de graduação. Os motivos mais recorrentes de satisfação foram o estudo e conhecimento proporcionados, a possibilidade de ter contato com pacientes, a remuneração e, por fim, a maturidade.

"Ele me satisfez por me dar uma base humanística e acesso a conhecimentos que eu não teria na faculdade de Medicina".

"Satisfez devido à vasta área de atuação e no desenvolvimento das relações terapeuta-paciente".

"Ele me satisfez no aspecto de me estruturar financeiramen$t e^{\prime \prime}$.

"O curso ampliou minha visão de mundo, das relações".

"O curso me proporcionou maturidade".

Os fatores de frustração mais citados foram financeiros e de empregabilidade, insegurança e falta de preparo, atuação limitada e atuação técnico-administrativa.

"O mercado de trabalho, a remuneração e a falta de relação do curso com a profissão é que foram frustrantes".

"[...] faltou segurança para atuação clínica".

"[...] limitação da realização legal de procedimentos".

"Me frustrei no mercado de trabalho quando vi que minha função era administrativa".

Questionados se acreditavam que o primeiro curso havia influenciado a escolha por Medicina, a maioria dos entrevistados $(63 \%)$ afirmou que sim. Entre os principais motivos de influência, a graduação anterior teria sido útil para confirmar o interesse pela área da saúde, por ter auxiliado na descoberta do interesse pela área médica, pelo ambiente hospitalar e pela convivência com médicos.

"[...] meu primeiro curso confirmou minha afinidade pela área da saúde".
"[...] foi importante para eu ter certeza do que eu não queria e assumir definitivamente o meu desejo".

"[...] descobri, então, meu interesse pelo cuidado e contato próximo com o paciente".

"[...] pude experimentar a relação terapeuta-paciente, a prática clínica, trabalhar numa equipe de saúde e percebi que gosto dessa dinâmica".

"[...] o contato com os profissionais médicos e enfermeiros me fez despertar o interesse".

A maior parte dos entrevistados (74\%) negou que a idade de ingresso no primeiro curso tenha influenciado a escolha de uma segunda profissão. Entre os que acreditam que houve influência, quase todos apontaram a insegurança e imaturidade na escolha da primeira graduação.

\footnotetext{
"Na idade em que entrei em farmácia eu não tinha maturidade, autoconhecimento e segurança suficientes para optar por medicina".

"[...] ter maturidade para saber o que realmente gostaria de exercer como profissão por toda a vida".

"Imaturidade para avaliar e ponderar a realidade de trabalho, a condição geral da profissão, a rotina e suas dificuldades e beneficios".
}

Considerando que de alguma forma a graduação anterior poderia influenciar no curso atual, os alunos foram questionados sobre como se dava essa influência, em dois quesitos. Em relação à análise crítica e métodos de estudo, os entrevistados afirmaram ter maior e melhor capacidade de valorizar conceitos e conteúdos, melhor capacidade de aprendizado e de raciocínio, além de já possuírem conhecimento prévio na área.

\footnotetext{
"O primeiro curso ampliou consideravelmente minha capacidade de compreender a importância futura de certos conteúdos".

"Permite uma visão mais crítica e melhor compreensão dos conteúdos e métodos".

"O conhecimento prévio também facilitou o entendimento de muitos assuntos durante o curso".

"Acredito ter facilidade, pois muitas vezes o conteúdo apresentado, embora com enfoque diferente, já fez parte da minha rotina de trabalho".
}

A respeito das relações sociais, os graduandos consideraram que a maior influência foi facilidade de aproximação com os pacientes, seguida de maturidade no estabelecimento das relações, mas certo distanciamento com colegas de turma. 
"[...] mais desenvoltura e menos constrangimento para lidar com algumas situações perante os pacientes que os meus colegas".

"Melhor maturidade, capacidade crítica e habilidades previamente desenvolvidas para relacionar-se com os pacientes".

"É como se você já tivesse um determinado manejo para lidar com as situações que aparecem".

"[...] tenho preguiça de muitos colegas mais imaturos".

"A diferença etária e de interesse prejudica relação entre colegas".

As principais dificuldades para cursar Medicina se associavam a carga horária excessiva, questões financeiras e incompatibilidade de tempo para trabalhar e estudar. Entre as estratégias para superar tais dificuldades, a única que se destacou foi o planejamento e a otimização do tempo livre.

"Gostaria de ter mais tempo para estudar e praticar atividades extracurriculares".

"Impossibilidade de ajudar financeiramente em casa, pela impossibilidade de adequar o horário da faculdade com o de algum serviço".

"Principalmente financeira, porque é difícil depender dos pais, pois é um curso que tem uma carga horária grande, além de ser um curso que necessita de uma demanda de muito estudo, ficando assim difícil trabalhar e estudar".

"Como trabalho, o tempo disponível para estudo extraclasse é reduzido".

"Planejamento diário, seguindo à risca critério de priorida$d e^{\prime \prime}$.

"Eu tenho pouquíssimo tempo para estudar e, por isso, tenho que planejar bem meu tempo".

Quanto às expectativas para a futura profissão, grande parte dos entrevistados acredita que obterá remuneração satisfatória e realização profissional e pessoal, além de conseguir assistir o paciente integralmente e encontrar melhores oportunidades no mercado de trabalho.

"Total realização profissional e emprego imediato".

"Realização, satisfação profissional e remuneração adequada para ter uma vida confortável".

"Espero ter maior reconhecimento dos pacientes, poder ajudá-los e ter uma condição financeira melhor do que eu teria com as outras profissões".

"[...] voltar para minha comunidade e minimizar essa ausência constante de médico que queira trabalhar. Ter um bom salário para sustentar minha família, construir uma casa".
$\mathrm{Na}$ última pergunta do questionário, solicitava-se aos estudantes que explicitassem os planejamentos de curto e de longo prazo após a formatura. De imediato, a maioria deseja trabalhar, seja em Programa de Saúde da Família (PSF) ou em serviços de urgência. Ingressar em uma residência médica, de preferência logo após a conclusão da graduação, foi o segundo mais lembrado.

\footnotetext{
"Pretendo trabalhar com medicina de família e urgência e estudar para residência".

"Após me formar, pretendo começar a trabalhar como generalista, acumular algum dinheiro".

"Entrada imediata na residência médica".

"Após a residência, se possível, já quero passar na prova de residência em Clínica Médica".
}

Como meta de longo prazo, ingressar em uma residência foi o mais desejado. A carreira acadêmica, incluindo mestrado, doutorado e tornar-se professor universitário, e se estabilizar financeiramente também foram muito lembrados.

\author{
"[...] fazer mestrado, doutorado e dar aula em faculdade". \\ "Cursar residência médica, fazer mestrado e dar aula". \\ "Chegar a um nível em que exerceria a medicina sem me pre- \\ ocupar com renda". \\ "Fazer residência". \\ "Concluir a residência". \\ "Carreira acadêmica e clínica".
}

\section{DISCUSSÃO}

A idade média dos graduados que ingressaram em Medicina neste estudo foi de 29 anos, diferentemente daquela encontrada em estudos internacionais, 23 e 24 anos $^{4,5}$. Da mesma forma, as médias de ingresso no primeiro curso superior foram aos 20 anos, enquanto em outros países se situaram entre 17 e 18 anos $^{4,5}$.

Diferentes processos de acesso à escola médica em outros países onde os estudos foram feitos podem resultar em diferenças na idade de início do curso médico. Embora no Brasil haja programas de obtenção de novo título nas universidades, eles geralmente são restritos ao preenchimento de poucas vagas remanescentes. Em alguns países, como Estados Unidos da América, Inglaterra, Austrália e Nova Zelândia, há programas exclusivos para a inclusão de alunos já graduados no curso de Medicina. O principal argumento dessa proposta é o aumento da diversidade, tanto social quanto psicológica, nos cursos médicos?.

Nos Estados Unidos da América, os candidatos às escolas médicas devem ter cursado quatro anos em disciplinas em 
áreas relacionadas à Medicina, como Biologia, Química Geral ou Química Orgânica, chamadas "pré-med". Na prática, o candidato completa um bacharelado em alguma área relacionada à Medicina como pré-requisito para ingressar em um curso médico por mais quatro anos ${ }^{10}$. No Reino Unido, para ingressar nas escolas médicas como primeira graduação, ele deve possuir boas notas, boa avaliação pessoal e passar por entrevista, e a duração do curso é de, no mínimo, seis anos. No caso de já possuir uma graduação, pode se candidatar a um programa (Graduate Entry Program) de quatro anos, com a obtenção da mesma qualificação do ensino padrão, de seis $\operatorname{anos}^{11,12}$. Há programas semelhantes em outros países, como a Austrália, que oferece um curso de quatro anos para formação de médicos já graduados em outras áreas ${ }^{13}$.

Além disso, o amadurecimento da ideia de enfrentar um novo curso de graduação e as dificuldades para iniciá-lo em universidades públicas podem ser fatores importantes na determinação de idade maior entre esses estudantes quando comparados aos de outros países. Deve-se considerar também que, após a primeira graduação, a maioria dos entrevistados (quase $80 \%$ ) afirmou ter exercido a profissão por cerca de quatro anos; cerca de $40 \%$ já possuíam alguma pós-graduação e $22 \%$ já haviam iniciado outro curso antes de optar pela Medicina como nova graduação.

Pesquisar as motivações pode ser uma forma de entender como o universo da Medicina é percebido pelos alunos. Em estudo australiano, as principais motivações para ingressar em Medicina como segundo curso de graduação foram, em ordem decrescente, a necessidade de trabalhar com pessoas, satisfação intelectual e a vontade de ajudar os outros ${ }^{6}$. Na Faculdade de Medicina da UFMG, estudo realizado com alunos do início do ciclo profissional mostrou que as principais motivações para estudar Medicina foram: ajudar e servir ou trabalhar com pessoas, boa empregabilidade e bons salários $^{2}$, embora um estudo anterior na mesma faculdade tenha mostrado as razões pessoais, seguidas pelo desejo de ajudar o outro (altruísmo) como as motivações principais. Segundo os autores desse último estudo, a proteção da família, muitas vezes com boas condições econômicas, talvez tenha feito com que menos de $5 \%$ indicassem preocupação com o mercado de trabalho ${ }^{3}$. Neste estudo, a principal motivação para a escolha da Medicina se relacionou à insatisfação pessoal com a primeira profissão. Salientam-se também, entre as motivações, o melhor mercado de trabalho e melhores salários e, entre os profissionais da área de saúde, a percepção de maior autonomia e poder do médico frente aos demais. Isso permite inferir que muitos desses estudantes, por já terem uma vivência prévia, expressam maior preocupação com o retorno financeiro e com a inserção que a futura profissão irá oferecer após a formatura, isto é, uma visão menos utópica do exercício da medicina.

As frustrações com o primeiro curso, em razão de baixa empregabilidade e remuneração financeira insatisfatória, influenciaram a escolha da Medicina. De acordo com o Instituto de Pesquisa Econômica Aplicada (Ipea), medicina é a carreira com melhor remuneração (média de $\mathrm{R} \$ 8.459,45$ ) e maior ocupação (97\%) no País. Entre as profissões da saúde apenas, a segunda com melhor ocupação (96\%) é a odontologia, seguida por farmácia (94\%), profissões de reabilitação, serviço social, psicologia e enfermagem (cerca de 93\%), biologia (92\%) e educação física (90\%). A odontologia é a segunda com melhor salário ( $\mathrm{R} \$ 5.367,31)$, seguida por farmácia ( $\mathrm{R} \$ 4.067,68)$, psicologia ( $\mathrm{R} \$ 3.600,10)$, enfermagem ( $\mathrm{R} \$ 3.495,07)$, reabilitação (R\$3.087,01), serviço social ( $\mathrm{R}$ \$ 3.061,08) e educação física ( R\$ 2.786,31). Percebe-se que há discrepância não só na remuneração média como na ocupação das diversas profissões. A medicina mantém-se há uma década como a profissão com melhores resultados no ranking geral normalizado - análise em conjunto dos atributos salário, empregabilidade, jornada de trabalho e previdência ${ }^{14}$.

Essa diversidade na remuneração e empregabilidade, associada à maior autonomia profissional existente na medicina quando comparada às demais profissões da área de saúde percebida por alguns dos participantes, favorece a migração para o curso de Medicina daqueles que se propõem a enfrentar o desafio de um novo curso superior.

O desejo antigo de ser médico, que aparece em 16\% das respostas, embora não tenha sido explorado em profundidade, poderia estar relacionado com altruísmo. Justificativas para não realização do sonho anteriormente foram a dificuldade de ingresso no curso de Medicina e a falta de condição econômica para cursá-lo.

A escolha da Medicina, muitas vezes, foi influenciada pelo primeiro curso, seja pela vivência do exercício profissional em ambientes hospitalares ou por meio do contato com pacientes. É possível que isso ajude a explicar por que a maior parte dos graduados é egressa de cursos da área biomédica, como Farmácia, Enfermagem e Ciências Biológicas.

Entre os participantes da pesquisa, 22\% iniciaram outro curso após a primeira graduação antes de decidirem fazer o curso de Medicina. Este dado não foi investigado de maneira aprofundada, mas algumas razões para isso podem ser inferidas. A imaturidade e a insegurança da escolha do primeiro curso foram apontadas como fatores para o início de uma segunda graduação. A escolha precoce de uma graduação sem conhecimento de opções de trabalho na profissão e do mercado de trabalho tem sido discutida ${ }^{15}$, sendo considerada tam- 
bém uma causa de evasão durante o curso superior, levando a trocas de cursos, às vezes sucessivas. Nesse sentido, propostas como a da chamada "universidade nova", com a inclusão de um ciclo inicial generalista, já há algum tempo têm sido discutidas, com opiniões divergentes ${ }^{16}$. A insatisfação com o exercício profissional, seja por dificuldade de inserção no mercado ou pela atividade em si, também deve ser considerada.

As dificuldades apontadas pelos graduados para a realização do curso foram a maior idade e os compromissos prévios. No estudo de Rapport e colaboradores, os graduados se queixaram de grandes impactos do curso principalmente sobre a vida social e das dificuldades para lidar com compromissos familiares, principalmente o cuidado com filhos e as responsabilidades financeiras ${ }^{7}$. Esses resultados são bem semelhantes aos do presente estudo, em que se destacam a excessiva carga horária do curso, a falta de tempo para trabalhar e a queda nos rendimentos como dificuldades encontradas pelos estudantes. A necessidade de ajudar em casa ou a dependência dos pais podem ser uma frustração para adultos que já haviam conquistado certa independência financeira, mesmo com a má remuneração da profissão anterior, apontada por muitos. A grande variação no valor sugerido para se manter leva a crer que haja uma diversidade do perfil socioeconômico dos estudantes já graduados. Um dos fatores que poderiam explicar esse fato é a utilização da profissão obtida na primeira graduação para custear, pelo menos parcialmente, o curso de Medicina.

No que diz respeito às relações interpessoais, alguns estudantes afirmaram ter dificuldades de se relacionar com colegas de curso devido à imaturidade deles e à diferença etária. Por outro lado, uma formação superior prévia foi considerada benéfica por proporcionar maturidade para lidar com as situações inerentes ao curso de Medicina, por permitir aprimorar métodos de estudo e a capacidade de raciocínio, por oferecer conhecimento prévio na área da saúde, quando a profissão anterior foi nessa área, e por facilitar a relação médico-paciente. A influência do primeiro curso sobre o aprendizado da medicina foi avaliada por Rapport e colaboradores ${ }^{7}$, que demonstraram alguns benefícios experimentados por graduados ao estudarem Medicina, como maior facilidade para compreender anatomia e fisiologia, e melhor relacionamento com o paciente, principalmente se a área de estudo do primeiro curso estava relacionada às ciências biológicas.

Estudantes já graduados em outros cursos expressam boa expectativa sobre melhor remuneração, melhor empregabilidade, sentir-se realizado profissional e pessoalmente, e conseguir ajudar integralmente os pacientes. Embora muitos desejem cursar uma pós-graduação logo após a conclusão do curso médico, uma parte deseja trabalhar e acumular renda ou ajudar nas contas da casa. Esses resultados foram semelhantes aos do estudo de Rapport, que mostrou que graduados apontam preocupação com a empregabilidade após se formarem, com qual especialização seguir e com a vida financeira e familiar ${ }^{7}$

Quando perguntados sobre o planejamento após a formatura, a maioria destacou a vontade de trabalhar tanto em PSF quanto em plantões em serviços de urgência. Isto pode ser explicado por serem esses os mercados disponíveis para o recém-formado. No exercício da medicina, a urgência e a Atenção Primária são áreas de atuação que exigem experiência profissional ainda não adquirida por um egresso da graduação em Medicina, mas, apesar disso, têm sido o principal acesso ao mercado de trabalho no Brasil. A residência médica foi a meta de longo prazo mais citada, seguida da carreira acadêmica. Em estudo de Ferreira e colaboradores ${ }^{3}$, o desejo de concluir uma residência médica foi afirmado por quase todos os alunos do curso de Medicina da mesma faculdade. $\mathrm{O}$ fato de já haver alunos que fizeram cursos de pós-graduação entre os que responderam poderia explicar o interesse pela carreira acadêmica.

Vale a pena registrar a percepção dos autores de que, durante a abordagem aos alunos graduados, houve curiosidade a respeito do que os colegas já haviam respondido. Essa curiosidade talvez possa representar uma necessidade de se identificar enquanto grupo, com dificuldades, motivações e esperanças semelhantes.

\section{CONCLUSÃO}

A medicina ainda se mantém como um sonho para muitos estudantes, inclusive entre os que já possuem uma primeira graduação. Os graduados ingressam no curso médico em busca de maior valorização pessoal e profissional não alcançada no primeiro curso, principalmente por meio de melhor remuneração e empregabilidade e maior poder de atuação. Embora completar um curso superior traga benefícios ao se ingressar num segundo, há também dificuldades, uma vez que muitos alunos já constituíram família ou precisam trabalhar.

São necessários outros estudos que abordem as necessidades específicas dos estudantes graduados, com os objetivos de aproveitar seu conhecimento e vivências prévias no novo curso e adotar medidas que tornem menos árdua sua trajetória acadêmica.

\section{REFERÊNCIAS}

1. Millan LR, Azevedo RS, Rossi E, De Marco OL, Millan MP, de Arruda PC. What is behind a student's choice for becoming a doctor? Clinics. 2005; 60(2):143-50. 
2. Ribeiro, MMF, Leal SS, Diamantino FC, Bianchi HA. A opção pela medicina e os planos em relação ao futuro profissional de estudantes de uma faculdade pública brasileira. Rev. Bras. Educ. Med. 2011; 35(3):405-411.

3. Ferreira RA, Peret Filho LA, Goulart EMA, Valadão MMA. O estudante de medicina da Universidade Federal de Minas Gerais: perfil e tendências. Rev. Assoc. Med. Bras. 2000; 46(3):224-231.

4. Carter YH, Peile E. Graduate entry medicine: high aspirations at birth. Clin Med. 2007; 7(2):143-7.

5. Rolfe IE, Ringland C, Pearson SA. Graduate entry to medical school? Testing some assumptions. Med Educ. 2004; 38(7):778-86.

6. Dodds AE, Reid KJ, Conn JJ, Elliott SL, McColl GJ. Comparing the academic performance of graduate- and undergraduate-entry medical students. Med Educ. 2010; 44(2):197-204.

7. Rapport F, Jones GF, Favell S, Bailey J, Gray L, Manning A, et al. What influences student experience of Graduate Entry Medicine? Qualitative findings from Swansea School of Medicine. Med Teach. 2009; 31(12): e580-5.

8. Universidade Federal de Minas Gerais. Faculdade de Medicina. O curso de Medicina da UFMG. [Acesso em 6 abr. 2016]. Disponível em: http://site.medicina.ufmg.br/ce$\operatorname{grad} /$ medicina/.

9. James D, Ferguson E, Powis D, Bore M, Munro D, Symonds I, Yates J. Graduate entry to medicine: widening psychological diversity. BMC Medical Education. 2009; 13(9):67-74.

10. Medicine in USA. [Acesso em 6 abr. 2016]. Disponível em: http: / / www.medicalstudyguide.com/medicine-in-usa. html.

11. Study Medicine in UK. [Acesso em 6 abr. 2016]. Disponível em: http://www.medicalstudyguide.com/medicine-in-uk.html.

12. Graduate Entry Medicine Courses (4-Years). [Acesso em 6 abr. 2016]. Disponível em http:/ / www.medschoolsonline. co.uk/graduate-entry-programme/.
13. Study Medicine in Australia. [Acesso em 6 abr. 2015]. Disponível em: http://www.medicalstudyguide.com/medicine-in-australia.html.

14. Brasil. Instituto de Pesquisa Econômica Aplicada (IPEA). Radar: tecnologia, produção e comércio exterior. n. 27, Brasília: jul. 2013. [acesso em 1 set. 2014]. Disponível em http:/ / www.ipea.gov.br/portal/images/stories/PDFs / radar/130703_radar27.pdf

15. Tigrinho LMV. Evasão escolar nas instituições de ensino superior. Revista Gestão Universitária [on line]. 2008. [Acesso em 2 set. 2014]. Disponível em: http:/ /www.gestaouniversitaria.com.br/artigos/evasao-escolar-nas-instituicoes-de-ensino-superior

16. Peixoto MG. A proposta da Universidade Nova - Encantos, Perigos e Armadilhas. [Acesso em 28 mar. 2016]. Disponível em: http:/ /www.contee.org.br/secretarias/educacionais/materia_56.htm.

\section{CONTRIBUIÇÃO DOS AUTORES}

Corrêa RD fez a proposta inicial do projeto e Ribeiro MMF orientou seu desenvolvimento. Ambos participaram com Gonçalves RCB, Oliveira LS e Silva VCM da elaboração do projeto, de sua submissão ao COEP- UFMG, da coleta e análise dos dados, da revisão da literatura e da redação do artigo.

\section{CONFLITO DE INTERESSES}

Os autores declaram não haver conflito de interesses.

\section{ENDEREÇO PARA CORRESPONDÊNCIA}

Maria Mônica Freitas Ribeiro

Av. Professor Alfredo Balena, 190 - sala 246

Santa Efigênia - Belo Horizonte

CEP 30130-100 - MG

E-mail: mmonica@medicina.ufmg.br 